\title{
Increased Pain Symptomatology Among Females vs. Males With Fragile X-Associated Tremor/Ataxia Syndrome
}

\author{
Devon Johnson ${ }^{1 *}$, Ellery Santos ${ }^{1}$, Kyoungmi Kim ${ }^{1,2}$, Matthew D. Ponzini ${ }^{1,2}$, \\ Yingratana A. McLennan ${ }^{1}$, Andrea Schneider ${ }^{1,3}$, Flora Tassone ${ }^{1,4}$ and \\ Randi J. Hagerman ${ }^{1,3}$ \\ ${ }^{1}$ Medical Investigation of Neurodevelopmental Disorders Institute, School of Medicine, University of California, Davis, Davis, \\ CA, United States, ${ }^{2}$ Division of Biostatistics, School of Medicine, University of California, Davis, Davis, CA, United States, \\ ${ }^{3}$ Department of Pediatrics, School of Medicine, University of California, Davis, Davis, CA, United States, ${ }^{4}$ Department of \\ Biochemistry and Molecular Medicine, School of Medicine, University of California, Davis, Davis, CA, United States
}

OPEN ACCESS

Edited by:

Javier Pagonabarraga, Hospital de la Santa Creu i Sant

Pau, Spain

Reviewed by:

Gentian Vyshka,

University of Medicine, Tirana, Albania Jinkuk Hong,

University of Wisconsin-Madison, United States

Laia Rodriguez-Revenga, Hospital Clínic de Barcelona, Spain

*Correspondence:

Devon Johnson

ucbdevon@gmail.com

Specialty section:

This article was submitted to

Child and Adolescent Psychiatry,

a section of the journa

Frontiers in Psychiatry

Received: 23 August 2021 Accepted: 27 December 2021

Published: 20 January 2022

Citation:

Johnson D, Santos E, Kim K, Ponzini MD, McLennan YA,

Schneider A, Tassone F and Hagerman RJ (2022) Increased Pain Symptomatology Among Females vs.

Males With Fragile X-Associated

Tremor/Ataxia Syndrome.

Front. Psychiatry 12:762915

doi: 10.3389/fpsyt.2021.762915
Individuals with the fragile $X$ premutation report symptoms of chronic pain from multiple systems, have increased incidence of comorbid conditions where pain is a prominent feature, and pathophysiology that supports disrupted pain regulation, inflammation, and energy imbalance. Less is known about how pain manifests for the subpopulation of carriers that develop the motor and cognitive changes of fragile $\mathrm{X}$-associated tremor and ataxia syndrome (FXTAS), and how pain may differ between men and women. We gathered data collected from 104 males and females with FXTAS related to chronic pain, comorbid conditions related to pain, and medications used for pain control to further explore the types of pain experienced and to better characterize how individuals with the fragile $X$ premutation experience pain sensation across genders. We found that women experience significantly more pain symptoms than men, particularly allodynia (20 vs. $2.0 \%, p=0.008$ ), peripheral neuropathy pain (43.9 vs. $25.4 \%, p=0.0488$ ), migraine (43.9 vs. $14.5 \%, p=0.0008$ ), fibromyalgia ( 26.8 vs. $0 \%, p=0.0071$ ) and back pain (48.5 vs. $23.4 \%, p=0.008$ ). We found onset of peripheral neuropathy predicts the onset of ataxia $(\beta=0.63 \pm 0.25, p=0.019)$ and tremor $(\beta=0.56 \pm 0.17, p=0.004)$ across gender. Women also report significantly more anxiety (82.9 vs. $39.7 \%, p<$ $0.001)$, which has implications for ideal pain treatment. These pain symptoms need to be recognized in the medical history and treated appropriately, with consideration for overlapping comorbidities.

Keywords: FXTAS, pain, premutation, FMRP, fibromyalgia, neuropathy, migraine, anxiety

\section{INTRODUCTION}

The fragile $\mathrm{X}$ premutation is a genetic condition characterized by an increased number of trinucleotide repeats (55-200 CGG repeats) in the FMR1 gene, which encodes for the fragile $\mathrm{X}$ mental retardation protein (FMRP) central for neuronal development and synaptic plasticity in the central and peripheral nervous systems. Expansion of over 200 CGG repeats leads to hypermethylation and gene silencing resulting in the fragile $\mathrm{X}$ full mutation and fragile $\mathrm{X}$ syndrome 
(FXS). The premutation leads to enhanced levels of FMR1 mRNA from 2 to 8 times normal and the excess mRNA causes RNA toxicity including the sequestration of proteins important for neuronal function, oxidative stress, and mitochondrial dysfunction that eventually can lead to the fragile X-associated tremor ataxia syndrome (FXTAS) (1).

FXTAS is a late-onset neurodegenerative condition that occurs in approximately $40 \%$ of male and $16 \%$ of female carriers. FXTAS affects cognition and movement in individuals, typically males > females over age 50, with core features including: gait ataxia, intention tremor, parkinsonism, executive function deficits, neuropathy and dysautonomia (2). Females with FXTAS typically have less severe movement symptoms (3) and cognitive decline (4), likely because their second X chromosome with normal FMR1 expression protects the CNS. The percentage of cells with normal allele present on the active $\mathrm{X}$ chromosome is the activation ratio (AR) and higher $A R$ may be protective against some manifestations of FXTAS (5). However, females with FXTAS have higher rates of autoimmune conditions and psychiatric manifestations $(6,7)$. Radiological criteria for the diagnosis of FXTAS include the major findings of white matter lesions in the middle cerebellar peduncles (MCP sign) or brainstem, and the following minor signs: white matter disease in splenium of corpus callosum and/or cerebrum, and moderatesevere brain atrophy (2). Among females with FXTAS there exists high radiological variability; fewer females have the MCP sign ( $9 \%$ in females vs. $60 \%$ in males) but have more diffuse cerebral white matter changes, including at the pons (4).

Of significant interest are the high frequency of pain complaints, as well as comorbid conditions with chronic pain that often start prior to FXTAS onset and vary by gender. Peripheral neuropathy is common in FXTAS (3) and can be a presenting feature of the syndrome (8). Musculoskeletal pain is common; back pain (9) and general muscle pain can often lead to the diagnosis of fibromyalgia (10), especially in women where the prevalence of fibromyalgia has been found as high as $43 \%$ (11). In the general population, fibromyalgia typically ranges between 2.4 and $6.8 \%$ among women (12).

The prevalence of migraine in premutation females has been found to be 54.2 vs. $26.8 \%$ in males (13), whereas the prevalence among females in US general population is reported to be $20.7 \mathrm{vs}$. $9.7 \%$ in males (14). In addition, there exists a high prevalence of coexisting conditions related to pain such as psychiatric problems that present in childhood or adulthood $(7,15,16)$, sleep problems in up to a third of carriers $(17,18)$, and executive function deficits (19). These conditions often present prior to the diagnosis of FXTAS and are common.

Pain is generally classified by pain type- nociceptive and neuropathic pain, as well as at different levels-central, spinal cord gating, peripherally (20). Both nociceptive and neuropathic chronic pain are prevalent in individuals with FXTAS. Nociceptive pain is caused by mechanical or chemical damage to a body tissue such as skin, muscles, joints, or fascia; nociceptors signal the brain of the injury, leading to pain perception. Examples of nociceptive pain conditions include arthritis, musculoskeletal disorders, migraine, tension headache, and fibromyalgia. Neuropathic pain can be caused by direct damage to peripheral nerves such as in diabetic neuropathy or at the level of the CNS such as in a stroke, tumor, or neurodegenerative disease like Parkinson's disease or Multiple Sclerosis, which damage areas related to pain. Central sensitization describes a type of neuropathic pain that occurs when pain signals to the brain are pathologically amplified, resulting in a high level of pain stimuli experienced in response to normally non-painful touch stimuli (allodynia) as well as increased feeling of pain stimuli (hyperalgesia). In response, the threshold for sending a signal to the CNS increases resulting in limited signal (21). To compensate for diminished peripheral signal, the spinal cord greatly amplifies the signal it does receive via increasing synaptic efficacy of somatosensory neurons in the dorsal horn (22).

Previous research suggests that FMRP has a role in the development of nociceptive pain sensitization and chronic pain $(23,24)$, and is studied as a potential target for pain treatment (25). FMR1 knockout mice that produce no FMRP show decreased neuropathic pain, protection from nociceptive sensitization (26-28) or IL-6 induced allodynia (29), and protection from pain-induced emotional sequelae such as depression (24). FMRP is hypothesized to mediate translational control over allodynia and persistent nociceptive sensitization (29). The primary pathophysiology of FXTAS is thought to be through increased mRNA production and toxicity. Despite increased mRNA production, FMRP is paradoxically decreased as CGG repeats increase, likely secondary to less efficient translation due to excessive repeats $(30,31)$. Because individuals with FXTAS frequently complain of chronic pain we have surveyed 104 patients with FXTAS to clarify what types of pain occur in this disorder.

\section{MATERIALS AND METHODS}

\section{Participants}

This study was conducted at the Fragile $\mathrm{X}$ Research and Treatment Center of the MIND Institute, University of California, Davis Medical Center, with participants in the Genotype-Phenotype Relationships in Fragile-X families data set. Participants with FXTAS were identified through families of known members affected by fragile $\mathrm{X}$ syndrome, referral from physicians, and via self-referral. All participants gave written informed consent from the UCD IRB and were categorized by the stages of FXTAS (32): stage (0) no tremor/ataxia; (1) questionable tremor and/or ataxia; (2) mild tremor and/or balance problems with minimal interference in activities of daily living (ADLs); (3) moderate tremor and/or ataxia with significant interference in ADLs; (4) severe tremor and/or ataxia requiring a cane or walker; (5) requiring daily use of wheelchair; (6) bedridden. We have eight participants who do not meet the diagnostic criteria for FXTAS (2), although all have premutation and subtle neurological symptoms apart from one patient who has the MCP sign without tremor or ataxia, a phenomenon previously reported in five males (33). These patients likely represent the most subtle end of the spectrum involving neurological deficits in the premutation and are included for comparison purposes. Participants who reported medical conditions such as a history 
of stroke, head injury, or primary language other than English were excluded from the study.

\section{Clinical Assessment and Molecular Analysis}

Participants underwent medical and neurological evaluation to assess FXTAS diagnosis, stage, and FMR1 molecular studies for CGG repeat size and mRNA level. A medical history was taken at the time of visit to document FXTAS phenotype and symptoms including tremor and ataxia in addition to age of onset and severity, current and past medication use, self-reported anxiety and depression, musculoskeletal and autoimmune problems such as osteopenia, osteoporosis, osteoarthritis, rheumatoid arthritis, fibromyalgia, lupus, ANA positivity, and other immunological diseases. We collected data on restless legs syndrome, severe cramps, disc/spine problems, and muscle pain. Migraine with and without aura, age of onset, and frequency was collected along with symptoms of neuropathy, allodynia, back pain, and chronic pain in general. Activation ratio was measured using ratios of signal intensity with Southern blot as previously described (34). FMR1 CGG repeat allele length was quantified using a combination of both PCR and Southern blot analysis as previously described (35).

\section{Medication Grouping}

Pain medication categories were separated into nonoverlapping categories of opiate analgesics, non-opiate analgesics, cannabinoids, anesthetics, antimigraine, nerve pain, and muscle pain/relaxation. Non-opiate analgesics included non-steroidal anti-inflammatory drugs (NSAIDs) and acetaminophen. Anesthetics included lidocaine. The category of antimigraine medications did not overlap with other medications categories and contained triptans, topiramate, and botulinum injections. Nerve pain medications were based on first line treatments and include tricyclics, serotonin and norepinephrine reuptake inhibitors (SNRIs), and antiepileptic drugs (AEDs) including gabapentin, pregabalin, and carbamazepine. Muscle pain/relaxation medications included antispasticity and antispasmodic agents such as baclofen, tizanidine, and cyclobenzaprine.

\section{Statistical Analysis}

Statistical analyses of data were performed with an open-source $\mathrm{R}$ software. Results were expressed as mean \pm standard deviation (or error) of mean for continuous variables and proportion (\%) for categorical variables. For quantitative variables, group differences in means or medians were determined by $t$ test, analysis of variance (ANOVA), or Kruskal-Wallis test as appropriate. For categorical variables, proportions were compared between groups using $t$-test for proportions, chisquared test, or Fisher's exact test as appropriate. Linear regression analysis was performed to assess associations between two variables with the main effects of the predictor and gender and their interaction term included in the linear models. Missing values were excluded from the statistical inference tests. Two-tailed $p<0.05$ were considered statistically significant as appropriate.

\section{RESULTS}

\section{Clinical Characteristics}

The participants are 104 individuals (41 female and 63 male) with FXTAS and the premutation confirmed via molecular studies. No significant gender difference was found for race and ethnicity $(p=0.513)$, education level $(p=0.199)$, age $(p=0.743)$, CGG repeat size $(p=0.266)$, or FXTAS stage $(p=0.404)$. The mean (SD) age of females was 68.1 (8.8) years and age of males was $67.5(8.0)$ years. Race and ethnicity are primarily white $(100 \%$ female vs. $95.7 \%$ male). Of the 41 females in the study, 34 $(85 \%)$ are FXTAS stage $>2$. Of the 63 males, $57(90.5 \%)$ are FXTAS stage $>2$. The mean CGG repeat size for females is 87 $(\mathrm{SD}=18)$, and the mean for males is $90(\mathrm{SD}=16)$. Refer to Table 1. There is a significant difference in FXTAS diagnostic categories ( $p=0.001$ ) with more males diagnosed with "Definite FXTAS" than females (48.3\% male vs. 9.8\% female). Females are more represented in the Probable category (30.0\% male vs. $58.5 \%$ female).

\section{Age of Symptom Onset}

Mean age of onset of migraine is 28.7 years $(S D=17.6)$, chronic pain is 51.4 years $(\mathrm{SD}=17.3)$, peripheral neuropathy is 57.4 years $(\mathrm{SD}=11.4)$, tremor is 58.6 years $(\mathrm{SD}=9.2)$, and ataxia is 60.7 (9.4), and no gender differences were found (see Table $\mathbf{1}$ ).

The age of onset of peripheral neuropathy symptoms was positively associated with the age of onset of ataxia $(\beta=0.56 \pm$ $0.17, p=0.004)$ and tremor $(\beta=0.56 \pm 0.17, p=0.004)$. There were no significant associations between the onset of chronic pain and migraine with the onset of ataxia and tremor (see Table 2 and Figure 1). In addition, there were no gender differences for any of those associations.

\section{Pain Prevalence in FXTAS}

There were significant gender differences in the prevalence of several symptoms. Back pain was significantly higher in females than males ( 48.5 vs. $23.4 \%, p=0.008$ ), as was migraine (43.9 vs. $14.5 \%, p=0.0008$ ), fibromyalgia (26.8 vs. $0 \%, p=0.0071)$, thyroid problems (34.2 vs. $14.5 \%, p=$ 0.0182 ), osteoarthritis ( 65.9 vs. $43.5 \%, p=0.027$ ), allodynia (20 vs. $2.0 \%, p=0.008$ ), peripheral neuropathy pain (43.9 vs. $25.4 \%, p=0.0488$ ), and anxiety ( 82.9 vs. $39.7 \%, p<0.001$ ). No significant gender differences were found in autoimmune problems, musculoskeletal pain, or depression (see Table 3).

\section{CGG Repeat and Pain}

Among participants who experienced pain, there were no gender differences in CGG repeat length. Among participants who had experienced autoimmune problems, there was a significant gender difference in CGG repeat length. Females with autoimmune had significantly lower CGG repeats than that of males $(76.5 \pm 12.9$ female vs. $105.5 \pm 26.5$ male, $p=0.032)$. Refer to Supplementary Table 4.

\section{Musculoskeletal vs. Neuropathic Pain}

Overall, the prevalence of patients with musculoskeletal pain (severe cramps + muscle pain + arthritis + back pain + disc or spine problems) was significantly higher than the prevalence 

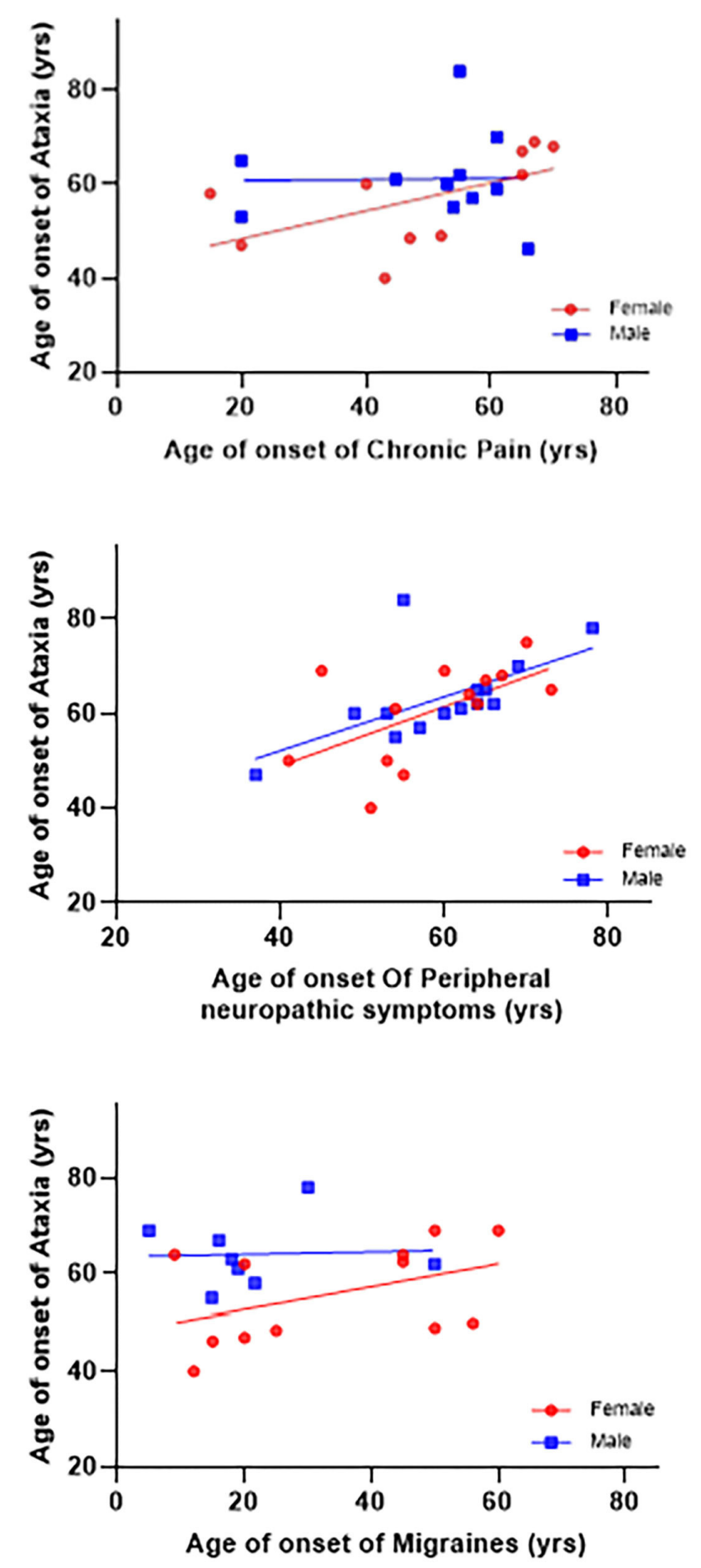
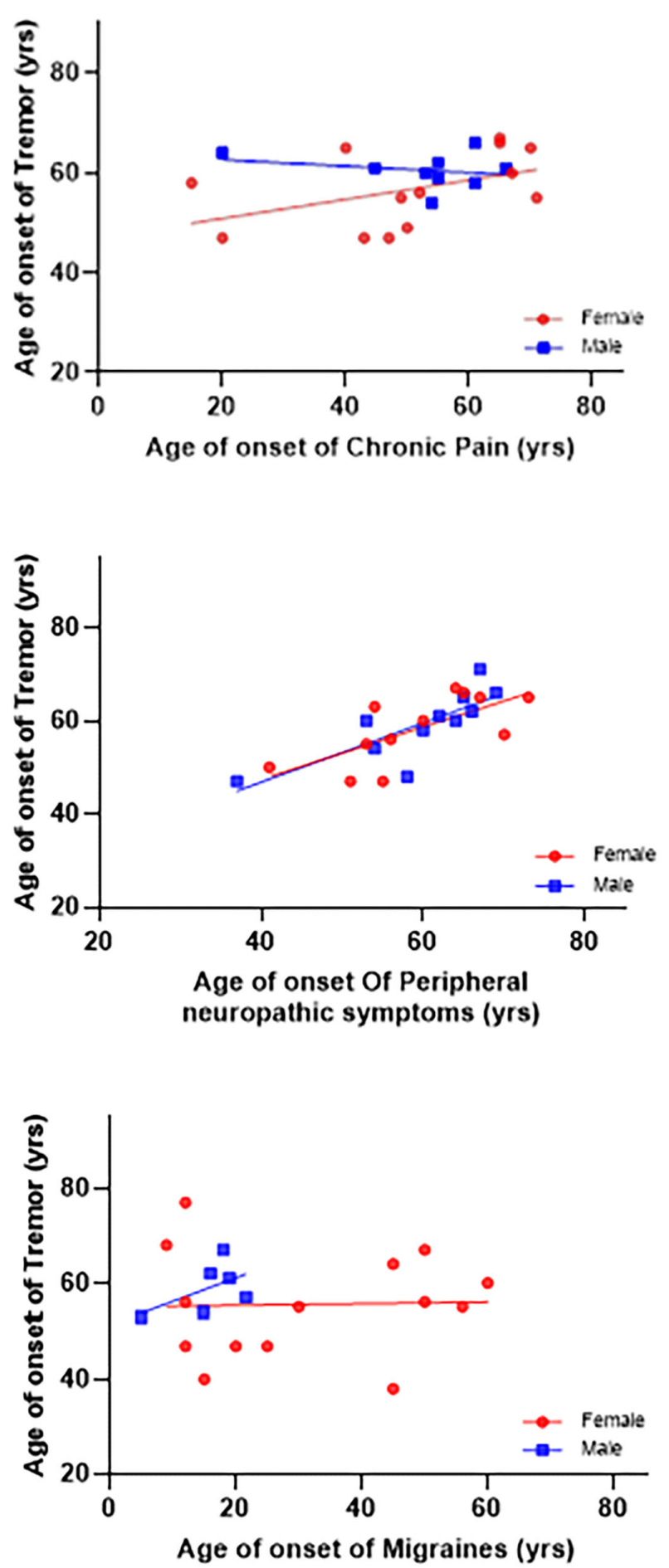

FIGURE 1 | Associations between ages of onset of symptoms and ataxia and tremor. The age of onset of peripheral neuropathy symptoms was positively associated with age of onset ataxia $(\beta=0.56 \pm 0.17, p=0.004)$ and tremor $(\beta=0.56 \pm 0.17, p=0.004)$. There were no significant associations between the onset of chronic pain and migraines with the onset of ataxia and tremor.

of patients with peripheral neuropathic pain (PNP) (88.4 vs. $33.7 \%, p<0.0001)$. The difference between the proportion with neuropathic pain and the proportion with musculoskeletal pain was significant in both males and females, $p=<0.0001$ (85.5 vs. $25.5 \%$ ) and $p=<0.0001$ ( 92.5 vs. $45 \%$ ), respectively (see Supplementary Table 5). 
TABLE 1 | Summary statistics [Mean \pm SD or N(\%)] of patient characteristics and age onset (years) of symptoms.

\begin{tabular}{|c|c|c|c|c|}
\hline & Total $(N=104)$ & Female $(N=41)$ & Male $(N=63)$ & $\begin{array}{c}\text { p-value (gender } \\
\text { difference) }\end{array}$ \\
\hline Age of visit (years) & $67.8 \pm 8.3$ & $68.1 \pm 8.8$ & $67.5 \pm 8.0$ & 0.7431 \\
\hline \multicolumn{5}{|l|}{ FXTAS stage } \\
\hline $0 / 1$ & $12(11.7 \%)$ & $6(15.0 \%)$ & $6(9.5 \%)$ & 0.5305 \\
\hline 2 & $23(22.3 \%)$ & $10(25.0 \%)$ & $13(20.6 \%)$ & 0.6335 \\
\hline 3 & 49 (47.6\%) & 17 (42.5\%) & $32(50.8 \%)$ & 0.4269 \\
\hline 4 & $13(12.6 \%)$ & $4(10.0 \%)$ & $9(14.3 \%)$ & 0.7619 \\
\hline 5 & $6(5.8 \%)$ & $3(7.5 \%)$ & $3(4.8 \%)$ & 0.6751 \\
\hline CGG repeat size & $89 \pm 16.4$ & $86.7 \pm 17.7$ & $90.4 \pm 15.5$ & 0.2802 \\
\hline \multicolumn{5}{|l|}{ Age of onset (years) } \\
\hline Tremor & $58.61 \pm 9.16$ & $58.83 \pm 9.36$ & $58.44 \pm 9.13$ & 0.8591 \\
\hline Ataxia & $60.71 \pm 9.44$ & $59.81 \pm 11.82$ & $61.33 \pm 7.48$ & 0.5011 \\
\hline Chronic pain & $51.36 \pm 17.3$ & $52.27 \pm 19.27$ & $50.15 \pm 15$ & 0.7541 \\
\hline Peripheral neuropathy symptoms & $57.36 \pm 11.36$ & $55.62 \pm 12.92$ & $59 \pm 9.79$ & 0.4021 \\
\hline Migraines & $28.73 \pm 17.63$ & $32.62 \pm 19.22$ & $21.8 \pm 12.49$ & 0.1441 \\
\hline
\end{tabular}

TABLE 2 | Associations between age onset of symptoms and age onset of ataxia and tremor.

\begin{tabular}{|c|c|c|c|c|c|c|c|c|}
\hline \multirow[t]{3}{*}{ Symptom } & \multicolumn{4}{|c|}{ Ataxia } & \multicolumn{4}{|c|}{ Tremor } \\
\hline & \multicolumn{2}{|c|}{ Main effect } & \multicolumn{2}{|c|}{ Gender difference } & \multicolumn{2}{|c|}{ Main effect } & \multicolumn{2}{|c|}{ Gender difference } \\
\hline & $\beta$ (SE) & $p$-value & $\beta$ (SE) & p-value & $\beta$ (SE) & p-value & $\beta$ (SE) & p-value \\
\hline Chronic pain & $0.3(0.17)$ & 0.091 & $-0.29(0.26)$ & 0.280 & $0.19(0.10)$ & 0.061 & $-0.26(0.18)$ & 0.178 \\
\hline Peripheral neuropathy symptoms & $0.63(0.25)$ & 0.019 & $-0.06(0.34)$ & 0.868 & $0.56(0.17)$ & 0.004 & $0.08(0.25)$ & 0.761 \\
\hline Migraines & $0.24(0.14)$ & 0.120 & $-0.21(0.29)$ & 0.480 & $0.02(0.15)$ & 0.908 & $0.48(0.81)$ & 0.567 \\
\hline
\end{tabular}

Bold values are $p$-values that have reached significance $(P<0.05)$ and are meant to draw the reader to the most important values.

\section{Activation Ratio and Pain}

The data does not provide evidence that activation ratio is significantly associated with either neuropathic pain or musculoskeletal pain, $p=0.241$ and $p=0.770$, respectively. The mean activation ratio for those with neuropathic pain is 0.52 , while the mean activation ratio is 0.60 for those without neuropathic pain. The mean activation ratio for those with musculoskeletal pain is 0.57 while the mean activation ratio is 0.61 for those without musculoskeletal pain (see Supplementary Table 6).

\section{Prevalence of Pain Medicine Usage}

Females with FXTAS are significantly more likely to be taking any pain medication ( $58.5 \%$ females vs. $36.5 \%$ males, $p=0.0271$ ) as well as nerve pain medication ( $31.7 \%$ females vs. $14.3 \%$ males, $p=0.331$ ). No significant gender differences were found for other medication types. Refer to Supplementary Table 7.

\section{DISCUSSION}

\section{Findings}

Both men and women with FXTAS experience chronic neuropathic and musculoskeletal pain. However, women with FXTAS experience significantly more chronic pain than men and take more pain medications. It's currently unclear why women with FXTAS experience more chronic pain than men, particularly central sensitivity syndromes, neuropathic pain, and back pain. Possible mechanisms include differences in endocrinology, autoimmune conditions, connective tissue, inflammation, and neuropsychiatric differences.

\section{Central Sensitivity}

Females with FXTAS were more likely to have conditions that fit under the umbrella of central sensitivity syndromes, characterized by altered pain regulation such as fibromyalgia, allodynia, chronic pain, and chronic headaches (6). We also found that the defining symptom of central sensitization, allodynia, is significantly higher in women with FXTAS $(p=0.008)$. Sensitization occurs following intense or chronic peripheral noxious stimuli, tissue injury, or nerve damage that keeps the peripheral nervous system in a constant state of activity. Chronic pain conditions commonly known to lead to hypersensitivity such as back pain, arthritis, and fibromyalgia are significantly prevalent among women with FXTAS. Central sensitivity symptoms are heavily influenced by psychological stressors (21), which are significantly worse for females with FXTAS in our cohort. Despite the known role of FMRP in altering sensitization of pain and neuropathy in animal models, we did not find that these pain phenotypes correlated with CGG repeat length. 
TABLE 3 | Prevalence [N of Yes (\%)] of symptoms (Yes/No).

\begin{tabular}{lcccc}
\hline Symptoms & Total $(\mathbf{N}=\mathbf{1 0 4})$ & Female $(\mathbf{N}=\mathbf{4 1})$ & Male $(\mathbf{N}=\mathbf{6 3})$ & $\boldsymbol{p}$-value (gender difference) \\
\hline Back pain & $27(33.8 \%)$ & $16(48.5 \%)$ & $11(23.4 \%)$ & $\mathbf{0 . 0 0 8}$ \\
Migraines & $27(26.2 \%)$ & $18(43.9 \%)$ & $9(14.5 \%)$ & $\mathbf{0 . 0 0 0 8}$ \\
Fibromyalgia & $11(10.9 \%)$ & $11(26.8 \%)$ & $0(0 \%)$ & $\mathbf{0 . 0 0 7 1}$ \\
Autoimmune & $10(12.3 \%)$ & $6(16.7 \%)$ & $4(8.9 \%)$ & 0.2301 \\
Thyroid problems & $22(22 \%)$ & $13(34.2 \%)$ & $9(14.5 \%)$ & $\mathbf{0 . 0 1 8 2}$ \\
Osteoarthritis & $54(52.4 \%)$ & $27(65.9 \%)$ & $27(43.5 \%)$ & $\mathbf{0 . 0 2 7}$ \\
Musculoskeletal pain & $86(88.7 \%)$ & $37(92.5 \%)$ & $49(86 \%)$ & 0.3077 \\
Peripheral neuropathy pain & $33(33.0 \%)$ & $18(43.9 \%)$ & $15(25.4 \%)$ & $\mathbf{0 . 0 4 8 8}$ \\
Allodynia & $8(9.5 \%)$ & $7(20.0 \%)$ & $25(39.7 \%)$ & $\mathbf{0 . 0 0 8}$ \\
Anxiety & $59(56.7 \%)$ & $34(82.9 \%)$ & $16(25.8 \%)$ & $\mathbf{0 . 0 0 1}$ \\
Depression & $26(25.2 \%)$ & $10(24.4 \%)$ & 0.413
\end{tabular}

Bold values are $p$-values that have reached significance $(P<0.05)$ and are meant to draw the reader to the most important values.

\section{Migraine}

We found a quarter of participants (26.2\%) reported experiencing migraines, with rates significantly higher among females than males $(43.9 \%$ females vs. $14.5 \%$ males, $p=0.0008)$. Age of migraine onset had no bearing over age of ataxia and tremor onset. This confirms a previous study on FMR1 premutation carriers and the prevalence of migraines (13). Author Au hypothesized that migraines in FXTAS are related to mitochondrial dysfunction leading to increased oxidative stress, which worsens with age. Several chronic pain syndromes prevalent in female FMR1 premutation carriers are comorbid with migraine including fibromyalgia (36), allodynia (37), and chronic fatigue syndrome (36), suggesting diffuse alterations to the nociceptive nervous system. Individuals with migraines are also at an increased risk for anxiety and depression (38).

\section{Psychiatric}

We found that women with FXTAS self-reported significantly more anxiety symptoms $(82.9 \%$ females vs. $39.7 \%$ males, $p=0.001$ ); depressive symptoms were present in a quarter of participants $(24.4 \%$ female vs. $25.8 \%$ male). This finding is consistent with previous studies that found women with FXTAS have more depression and emotional symptoms $(4,7)$. The relationship between pain and psychopathology is multidirectional; chronic pain is a strong predictor of both onset and persistence of comorbid psychiatric disorders in general, and vice versa, psychiatric disorders are also a powerful predictor of chronic pain persistence (39-41). Emotional states can also amplify the pain felt from central sensitivity syndromes (21). Women with FXTAS may report more chronic pain partly because that pain is viewed through a lens intensified by symptoms of anxiety, which play a role in pain perception (42). How significant a role mental health plays in FXTAS across gender may also be influenced by reporting bias, as men are less likely to disclose mental health problems than women in general (43).

\section{Hormonal}

Consistent with previous research on bone density in premutation carriers $(44,45)$, females were found to have more skeletal related problems such as osteopenia, osteoporosis, and osteoarthritis. With respect to pain, women with FXTAS reported significantly more back pain than men $(48.5 \%$ of women vs. $23.4 \%$ of men, $p=0.008$ ). Refer to Table 3. Postmenopausal women in the general population do tend to have higher incidence of back pain than men $(46,47)$, but percentages are similar between men and women in the 65-74 age group within the US (48). The cause of these gender differences is likely secondary to hormonal differences in post-menopausal women. The role estrogen plays in bone density is additionally important for women with the premutation because the mean age of natural menopause is reduced by about 5 years, from the typical age of about 51 to 46 . Separate from this overall earlier menopause, $20 \%$ of carriers (49) can develop fragile X-associated primary ovarian insufficiency (FXPOI) with typically onset at 33 years (50). This directly decreases the lifetime exposure of estrogen and decreases bone mineral density, as early menopause is associated with osteoporosis (51). The significantly increased back pain among women is likely secondary to decreased bone density-related sequelae, which can have a devastating impact on women with FXTAS.

\section{Neuropathy}

More women report feeling peripheral neuropathic pain than men ( 43.9 vs. $25.4 \%, p=0.0488$ ). Women were also more likely to be taking medications that treat nerve pain (31.7 vs. $14.3 \%, p=0.0331$ ), however some of these medications overlap with treatment for anxiety, which was also significant among women with FXTAS. We did not find CGG repeat number correlated with nerve pain in men or women. Nerve conduction studies have shown men and women have similar sensory nerve fiber abnormalities (52), but men have additional motor nerve abnormalities in conduction velocity and latency (53). Pathogenesis of neuropathy is related to RNA toxicity causing the creation of intracellular inclusion bodies in neurons and glial cells $(54)$ and peripheral tissues $(55,56)$ that causes axonal dysfunction.

Consistent with previous research that neuropathy is a presenting feature of FXTAS (8), we found the age onset of peripheral neuropathy was positively associated with the age 
onset of ataxia $(\beta=0.63 \pm 0.25, p=0.019)$ and tremor $(\beta=$ $0.56 \pm 0.17, p=0.004)$, with no gender difference. This further supports the recommendation to consider a FXTAS diagnosis in a patient presenting with neuropathy and a family history of intellectual disability, premature ovarian failure, autism, or movement disorder (8).

\section{Connective Tissue}

We found that musculoskeletal pain is significantly more prevalent than peripheral neuropathy pain (88.4 vs. $33.7 \%$, $p<$ 0.0001 ) in FXTAS. There was no significant gender difference in musculoskeletal pain ( 92.5 vs. $85.5 \%, p=0.3077$ ). Of interest, every patient that reported neuropathic pain also reported musculoskeletal pain, meaning all who experienced neuropathic pain also reported arthritis, back pain, severe cramping, or muscle pains. However, $54.7 \%$ of those with musculoskeletal pain did not have neuropathic pain (see Supplementary Table 6). Clinically, premutation carriers can manifest connective tissuerelated features such as hyperextensible finger joints, large ears, and connective tissue dysplasia that are more subtle than those seen in FXS (57). Case report evidence including five females with premutation and Ehlers Danlos syndrome phenotype suggests there may be related commonalities in pathogenesis (58). Possible pathophysiologic mechanisms hypothesized include FMRP deficiency, mRNA toxicity, and sex effects (58). FMRP is known to regulate multiple connective tissue pathways including elastin, actin, and matrix metalloproteinase (MMP9), a class of enzymes involved in bone development, wound healing, and pathology such as arthritis and intracerebral hemorrhage (59, $60)$. Levels of connective tissue involvement correlate with level of FMRP depletion in FXS and premutation CGG repeats > 120 are more likely to be associated with connective tissue problems (61). Because the FXTAS population has minimal alterations to FMRP which result in altered regulation of these pathways, this mechanism could contribute to generating chronic musculoskeletal pain in FXTAS.

\section{Autoimmune}

We did not find a significant gender difference $(p=0.2301)$ in rheumatoid arthritis, systemic lupus erythematosus, or antinuclear antibodies positivity, but the prevalence for these conditions was quite low. Confirming previous research, we found FXTAS women are more likely to have fibromyalgia (26.8 vs. $0 \%, p=0.0071$ ) and thyroid problems (34.2 vs. $14.5 \%$, $p=0.0182$ ). Fibromyalgia is generally thought to be immune mediated (62), but its etiology remains unclear with some evidence linking it to small nerve fiber neuropathy (63) and central sensitization (64). Thyroid problems consisted almost entirely of autoimmune causes, including hypo and hyperthyroid states. Females with autoimmune conditions had significantly lower CGG repeats than that of males, likely because women are more likely to have autoimmune conditions at baseline. Autoimmune conditions and inflammation have strong links to pain and the primary pathophysiology of FXTAS involves RNA toxicity and inflammation. Inflammatory mediators from damaged cells induce pain and sensitization. Local tissue inflammation can result in hypersensitivity to pain via secondary hyperalgesia, where inflammatory mediators diffuse to uninjured nearby tissues. Females produce a larger proinflammatory immune response to tissue damage than males (65). Females with FXTAS may have increased chronic pain because they develop more inflammation contributing to sensitization and maintenance of pain.

\section{Pain Treatment}

Non-opiate pharmacologic therapies can be selected based on type of pain (nociceptive, neuropathic, central sensitization, and combination) or by targeting comorbid conditions.

\section{Psychopharmacologic Overlap}

Considering both psychiatric and pain symptoms of a patient is crucial as psychiatric disorders can exacerbate pain conditions and impede treatment adherence (66). Treatment of depression and anxiety in fragile X-associated neuropsychiatric disorders (FXAND) typically involves SSRIs or SNRIs $(15,67)$. In addition to targeting symptoms of depression and anxiety, antidepressants such as tricyclics (TCAs), SSRIs, SNRIs, and norepinephrine dopamine reuptake inhibitors (NDRIs) have evidence for use in chronic pain and are commonly used in the treatment of patients with FXTAS. Of the antidepressants, evidence suggests SNRIs and TCAs are the most effective for treating chronic neuropathic pain (68) as well as centralized pain (21). There is also strong evidence for the use of anticonvulsants pregabalin and gabapentin, and with moderate evidence for use of SSRIs (21).

We recommend avoidance of opiates to treat chronic pain associated with FXTAS. Opiates are commonly used to treat pain in the general population and FXTAS population, but anecdotal evidence suggests those on opioids can have a faster progression of their FXTAS symptoms (69). Opiates are reported to trigger white matter changes in chronic users $(70,71)$. In vitro evidence suggests premutation neurons are more vulnerable to environmental toxins than normal neurons (67). Drug and alcohol use has been reported to be increased in premutation carriers compared to controls $(72,73)$, which has resulted in opiate overdose (74). Long-term opiate use leads to tolerance, dependence, withdrawal symptoms, and can worsen chronic pain through development of opiate-induced hyperalgesia (75).

Topical treatments can be recommended for chronic pain such as diclofenac and ketoprofen for musculoskeletal issues (76). For osteoarthritis, topical NSAIDs, low-concentration capsaicin, or topical rubefacients. For neuropathic pain, topical lidocaine or high-concentration capsaicin can be used.

\section{Emerging Pharmacotherapy}

$\mathrm{CBD}$ is a compound typically derived from hemp that targets $\mathrm{CB} 1, \mathrm{CB} 2$ receptors and is an allosteric modulator of $\mu$ - and $\delta$ opioid receptors. Evidence in FMR1 knockout mice suggests CB2 receptor is necessary for protection against neuropathic pain, raising interest in targeting this receptor for treatment (77). A controlled trial examined pain in patients with multiple sclerosis, spinal cord, and other neurological conditions found pain control improved with CBD (78) in addition to two other studies that found pain relief $(79,80)$. CBD is also being explored as an 
intervention in FXS (81) in an open-label trial (82) because of its benefits on sleep quality, anxiety (83), and cognitive impairment (84).

Curcumin is a polyphenol with anti-inflammatory properties extracted from turmeric that has shown promising preclinical results in treating FXTAS (85) but has not been studied clinically. Curcumin has a notable anti-inflammatory effect and pain relief for the treatment of general pain syndrome and osteoarthritis (86). However, more comprehensive long-term studies are needed, as many of the controlled trials are of low quality with industry funding. Sulforaphane is another dietary supplement with antioxidant/anti-inflammatory properties that was found to improve markers of oxidative stress and mitochondrial function in fibroblasts from FXTAS patients (87), but has not been studied for pain symptoms in FXTAS.

Allopregnanolone, a natural neurosteroid and positive allosteric modulator at GABA-A, has been studied as a safe therapy for neuropathic pain $(88,89)$, treatment for postpartum depression (90), and has been studied in an openlabel trial for treatment of FXTAS in six patients with limited benefits on executive function and neuropathy symptoms (91). Allopregnanolone is a promising candidate for FXTAS because it improves mitochondrial dysfunction and acts to prevent reactive oxidative species (ROS) overproduction, a primary pathological mechanism driving FXTAS phenotype. ROS produced in mitochondria have been shown to contribute to central sensitization associated with pain (92). Allopregnanolone was able to protect neuronal cells against oxidative stress through improved mitochondrial antioxidant activity (93).

\section{Non-pharmacologic}

For a non-pharmacologic approach, counseling and therapy for chronic pain and psychiatric conditions has been helpful. The cognitive behavioral therapy approach to pain teaches patients skills to anticipate pain and divert attention to other thoughts, helping the patient better cope with pain (94). We also recommend daily exercise to stimulate neurogenesis, improve mitochondrial function, and decrease chronic pain (67). Focusing on maintaining sleep quality can have an impact on pain (95). We recommend other techniques for reducing overall stress such as biofeedback for relaxation, which can lead to improvements in various pain-related outcomes (96). Mindfulness stress reduction has evidence for reducing chronic pain and improving quality of life (97). Acupuncture has been studied in hundreds of controlled trials and appears to be effective for chronic pain, particularly back pain (98) and headaches (99).

\section{Study Limitations}

The limitations of this study include a sample bias, as the cohort consisted of participants with higher socioeconomic status and majority with white ethnicity. Data on anxiety and depression are self-reported and the symptomatology of pain is recorded through medical interviews. Future studies characterizing pain would benefit from measures of intensity. Furthermore, participants were enrolled through referral from physicians or family members and thus this cohort might not be a true representative of individuals with FXTAS, but the more affected ones. In addition, men are less likely to disclose health issues, and at more advanced FXTAS stages may not be able to assess themselves accurately.

\section{CONCLUSION}

In conclusion, our results have important clinical implications for the treatment of female premutation carriers with FXTAS who have increased back pain, neuropathy, and central sensitization related pain. Pain is a significant finding in FXTAS and should be questioned in the medical history for all premutation carriers and treated appropriately.

\section{DATA AVAILABILITY STATEMENT}

The datasets presented in this study can be found in online repositories. The names of the repository/repositories and accession number(s) can be found at: https://redcap.ucdmc. ucdavis.edu/redcap/, CTSC\#3704. Further enquiries can be directed to the corresponding author.

\section{ETHICS STATEMENT}

The studies involving human participants were reviewed and approved by Institutional Review Board at the University of California Davis. The patients/participants provided their written informed consent to participate in this study.

\section{AUTHOR CONTRIBUTIONS}

ES, DJ, and RH conceived of the presented idea and questions. DJ developed the idea and wrote the manuscript with support from ES, RH, KK, and MP. KK and MP performed statistical computations and created figures and tables. YM, RH, ES, AS, and DJ collected data. FT conducted molecular studies. All authors contributed to the article and approved the submitted version.

\section{FUNDING}

This work was supported by NICHD Grant Number: HD036071, the Tides foundation and the MIND Institute IDDRC (Grant Number: U54 HD079125).

\section{ACKNOWLEDGMENTS}

We thank all the patients with FXTAS and families who participated in this research as well as our donors who have supported our research.

\section{SUPPLEMENTARY MATERIAL}

The Supplementary Material for this article can be found online at: https://www.frontiersin.org/articles/10.3389/fpsyt. 2021.762915/full\#supplementary-material 


\section{REFERENCES}

1. Hagerman RJ, Hagerman P. Fragile X-associated tremor/ataxia syndromefeatures, mechanisms and management. Nat Rev Neurol. (2016) 12:40312. doi: $10.1038 /$ nrneurol.2016.82

2. Hall DA, Birch RC, Anheim M, Jønch AE, Pintado E, O'Keefe J, et al. Emerging topics in FXTAS. J Neurodev Disord. (2014) 6:31. doi: 10.1186/1866-1955-6-31

3. Jacquemont S. Penetrance of the Fragile X-Associated Tremor/Ataxia Syndrome in a Premutation Carrier Population. JAMA. (2004) 291:460. doi: 10.1001/jama.291.4.460

4. Schneider A, Summers S, Tassone F, Seritan A, Hessl D, Hagerman P, et al. Women with fragile $\mathrm{x}$-associated tremor/ataxia syndrome. Mov Disord Clin Pract. (2020) 7:910-919. doi: 10.1002/mdc3.13084

5. Hall DA, Robertson-Dick EE, O'Keefe JA, Hadd AG, Zhou L, Berry-Kravis E. X-inactivation in the clinical phenotype of fragile $\mathrm{X}$ premutation carrier sisters. Neurol Genet. (2016) 2:e45. doi: 10.1212/NXG.0000000000000045

6. Winarni TI, Chonchaiya W, Sumekar TA, Ashwood P, Morales GM, Tassone $\mathrm{F}$, et al. Immune-mediated disorders among women carriers of fragile X premutation alleles. Am J Med Genet Part A. (2012) 158A:24732481. doi: 10.1002/ajmg.a.35569

7. Loesch DZ, Tassone F, Atkinson A, Stimpson P, Trost N, Pountney $\mathrm{DL}$, et al. Differential progression of motor dysfunction between male and female fragile $\mathrm{X}$ premutation carriers reveals novel aspects of sex-specific neural involvement. Front Mol Biosci. (2021) 7:577248. doi: 10.3389/fmolb.2020.577246

8. Hagerman RJ, Coffey SM, Maselli R, Soontarapornchai K, Brunberg JA, Leehey MA, et al. Neuropathy as a presenting feature in fragile X-associated tremor/ataxia syndrome. Am J Med Genet Part A. (2007) 143A:225660. doi: 10.1002/ajmg.a.31920

9. Salcedo-Arellano MJ, Cabal-Herrera AM, Tassanakijpanich N, McLennan YA, Hagerman RJ. Ataxia as the major manifestation of fragile Xassociated tremor/ataxia syndrome (FXTAS): case series. Biomedicines. (2020) 8:136. doi: 10.3390/biomedicines 8050136

10. Leehey MA, Legg W, Tassone F, Hagerman R. Fibromyalgia in fragile X mental retardation 1 gene premutation carriers. Rheumatology. (2011) 50:22332236. doi: 10.1093/rheumatology/ker273

11. Coffey SM, Cook K, Tartaglia N, Tassone F, Nguyen DV, Pan R, et al. Expanded clinical phenotype of women with theFMR1 premutation. Am J Med Genet Part A. (2008) 146A:1009-1016. doi: 10.1002/ajmg.a.32060

12. Marques AP, Santo A de S. do E, Berssaneti AA, Matsutani LA, Yuan SLK. Prevalence of fibromyalgia: literature review update. Rev Bras Reumatol. (2017) 57:356-63. doi: 10.1016/j.rbre.2017.01.005

13. Au J, Akins R, Berkowitz-Sutherland L, Tang H-T, Chen Y, Boyd A, et al. Prevalence and risk of migraine headaches in adult fragile $\mathrm{X}$ premutation carriers. Clin Genet. (2013) 84:546-551. doi: 10.1111/cge.12109

14. Burch R, Rizzoli P, Loder E. The Prevalence and impact of migraine and severe headache in the United States: figures and trends from government health studies. Headache. (2018) 58:496-505. doi: 10.1111/head.13281

15. Hagerman RJ, Protic D, Rajaratnam A, Salcedo-Arellano MJ, Aydin EY, Schneider A. Fragile X-associated neuropsychiatric disorders (FXAND). Front Psychiatry. (2018) 9:564. doi: 10.3389/fpsyt.2018.00564

16. Bourgeois JA, Seritan AL, Casillas EM, Hessl D, Schneider A, Yang Y, et al. Lifetime prevalence of mood and anxiety disorders in fragile $\mathrm{X}$ premutation carriers. J Clin Psychiatry. (2011) 72:175-82. doi: 10.4088/JCP.09m05407blu

17. Hamlin A, Liu Y, Nguyen D V, Tassone F, Zhang L, Hagerman RJ. Sleep apnea in fragile X premutation carriers with and without FXTAS. Am J Med Genet Part B Neuropsychiatr Genet. (2011) 156:923-8. doi: 10.1002/ajmg.b.31237

18. Summers SM, Cogswell J, Goodrich JE, Mu Y, Nguyen DV, Brass SD, et al. Prevalence of restless legs syndrome and sleep quality in carriers of the fragile X premutation. Clin Genet. (2014) 86:181-4. doi: 10.1111/cge.12249

19. Hall DA, Robertson E, Shelton AL, Losh MC, Mila M, Moreno EG, et al. Update on the clinical, radiographic, and neurobehavioral manifestations in FXTAS and FMR1 premutation carriers. Cerebellum. (2016) 15:57886. doi: 10.1007/s12311-016-0799-4

20. Merskey H, editor. Classification of chronic pain: Descriptions of chronic pain syndromes and definitions of pain terms. Pain. (1986) Suppl 3:226.
21. Dydyk AM, Givler A. Central Pain Syndrome. StatPearls (2021). Available online at: http://www.ncbi.nlm.nih.gov/pubmed/31971703 (accessed August 10, 2021).

22. Ji R-R, Kohno T, Moore KA, Woolf CJ. Central sensitization and LTP: do pain and memory share similar mechanisms? Trends Neurosci. (2003) 26:696-705. doi: 10.1016/j.tins.2003.09.017

23. Price TJ, Melemedjian OK. Fragile X mental retardation protein (FMRP) and the Spinal Sensory System. Results Problems Cell Differ. (2012). 54:41-59. doi: 10.1007/978-3-642-21649-7_4

24. Wang L, Almeida LEF, Nettleton M, Khaibullina A, Albani S, Kamimura $\mathrm{S}$, et al. Altered nocifensive behavior in animal models of autism spectrum disorder: the role of the nicotinic cholinergic system. Neuropharmacology. (2016) 111:323-34. doi: 10.1016/j.neuropharm.2016.09.013

25. Mei X, Yang Y, Zhao J, Wang Y, Chen Q, Qian X, et al. Role of fragile X mental retardation protein in chronic pain. Mol Pain. (2020) 16:1744806920928619. doi: 10.1177/1744806920928619

26. Price TJ, Rashid MH, Millecamps M, Sanoja R, Entrena JM, Cervero F. Decreased Nociceptive sensitization in mice lacking the fragile $\mathrm{X}$ mental retardation protein: role of mGluR1/5 and mTOR. J Neurosci. (2007) 27:13958-13967. doi: 10.1523/JNEUROSCI.4383-07.2007

27. Price TJ, Melemedjian OK. Fragile X Mental Retardation Protein (FMRP) and the Spinal Sensory System (2012).

28. Cea-Del Rio CA, Nunez-Parra A, Freedman SM, Kushner JK, Alexander AL, Restrepo D, et al. Disrupted inhibitory plasticity and homeostasis in Fragile X syndrome. Neurobiol Dis. (2020) 142:1-12. doi: 10.1016/j.nbd.2020.104959

29. Asiedu MN, Tillu DV, Melemedjian OK, Shy A, Sanoja R, Bodell $B$, et al. Spinal protein kinase $M$ underlies the maintenance mechanism of persistent nociceptive sensitization. J Neurosci. (2011) 31:6646-6653. doi: 10.1523/JNEUROSCI.6286-10.2011

30. Ludwig AL, Espinal GM, Pretto DI, Jamal AL, Arque G, Tassone F, et al. CNS expression of murine fragile $\mathrm{X}$ protein (FMRP) as a function of CGG-repeat size. Hum Mol Genet. (2014) 23:3228-38. doi: 10.1093/hmg/d du032

31. Primerano B, Tassone F, Hagerman RJ, Hagerman P, Amaldi F, Bagni C. Reduced FMR1 mRNA translation efficiency in fragile $\mathrm{X}$ patients with premutations. RNA. (2002) 8:1482-8.

32. Bacalman S, Farzin F, Bourgeois JA, Cogswell J, Goodlin-Jones BL, Gane LW, et al. Psychiatric phenotype of the Fragile X-associated tremor/ataxia syndrome (FXTAS) in males. J Clin Psychiatry. (2006) 67:8794. doi: 10.4088/JCP.v67n0112

33. Famula JL, McKenzie F, McLennan YA, Grigsby J, Tassone F, Hessl $\mathrm{D}$, et al. Presence of middle cerebellar peduncle sign in FMR1 premutation carriers without tremor and ataxia. Front Neurol. (2018) 9:695. doi: 10.3389/fneur.2018.00695

34. Tassone F, Hagerman RJ, Iklé DN, Dyer PN, Lampe M, Willemsen R, et al. FMRP expression as a potential prognostic indicator in fragile $\mathrm{X}$ syndrome. Am J Med Genet. (1999) 84:250-61.

35. Filipovic-Sadic S, Sah S, Chen L, Krosting J, Sekinger E, Zhang W, et al. A novel FMR1 PCR method for the routine detection of low abundance expanded alleles and full mutations in fragile X syndrome. Clin Chem. (2010) 56:399-408. doi: 10.1373/clinchem.2009.136101

36. Tietjen GE, Brandes JL, Peterlin BL, Eloff A, Dafer RM, Stein MR, et al. Allodynia in migraine: association with comorbid pain conditions. Headache. (2009) 49:1333-44. doi: 10.1111/j.1526-4610.2009.01521.x

37. Tietjen GE, Herial NA, Hardgrove J, Utley C, White L. Migraine comorbidity constellations. Headache. (2007) 47:85765. doi: 10.1111/j.1526-4610.2007.00814.x

38. Peres MFP, Mercante JPP, Tobo PR, Kamei H, Bigal ME. Anxiety and depression symptoms and migraine: a symptom-based approach research. $J$ Headache Pain. (2017) 18:37. doi: 10.1186/s10194-017-0742-1

39. Uçar M, Sarp Ü, Karaaslan Ö, Gül AI, Tanik N, Arik HO. Health anxiety and depression in patients with fibromyalgia syndrome. J Int Med Res. (2015) 43:679-85. doi: 10.1177/0300060515587578

40. Ciaramella A, Poli P. Chronic Low Back Pain: Perception and Coping With Pain in the Presence of Psychiatric Comorbidity. J Nerv Ment Dis. (2015) 203:632-40. doi: 10.1097/NMD.0000000000000340 
41. Gros DF, Szafranski DD, Brady KT, Back SE. Relations Between Pain, PTSD Symptoms, and Substance Use in Veterans. Psychiatry. (2015) 78:27787. doi: 10.1080/00332747.2015.1069659

42. Woo AK. Depression and Anxiety in Pain. Rev pain. (2010) 4:812. doi: $10.1177 / 204946371000400103$

43. Galdas PM, Cheater F, Marshall P. Men and health helpseeking behaviour: literature review. J Adv Nurs. (2005) 49:61623. doi: 10.1111/j.1365-2648.2004.03331.x

44. Hundscheid RDL, Smits APT, Thomas CMG, Kiemeney LALM, Braat DDM. Female carriers of fragile $\mathrm{X}$ premutations have no increased risk for additional diseases other than premature ovarian failure. Am J Med Genet A. (2003) 117A:6-9. doi: 10.1002/ajmg.a.10862

45. Allen EG, Sullivan AK, Marcus M, Small C, Dominguez C, Epstein $\mathrm{MP}$, et al. Examination of reproductive aging milestones among women who carry the FMRlpremutation. Hum Reprod. (2007) 22:2142-52. doi: 10.1093/humrep/dem148

46. Wáng YXJ, Wáng J-Q, Káplár Z. Increased low back pain prevalence in females than in males after menopause age: evidences based on synthetic literature review. Quant Imaging Med Surg. (2016) 6:199206. doi: 10.21037/qims.2016.04.06

47. Hoy DG, Raikoti T, Smith E, Tuzakana A, Gill T, Matikarai K, et al. Use of the global alliance for musculoskeletal health survey module for estimating the population prevalence of musculoskeletal pain: findings from the Solomon Islands. BMC Musculoskelet Disord. (2018) 19:292. doi: 10.1186/s12891-018-2198-0

48. QuickStats: Percentage* of adults aged $\geq 18$ years who had lower back pain in the past 3 months, ${ }^{\dagger}$ by sex and age group-national health interview survey,§ United States, 2018. MMWR Morb Mortal Wkly Rep. (2020) 68:1196. doi: 10.15585/mmwr.mm685152a5

49. Sherman SL. Premature ovarian failure in the fragile X syndrome. Am J Med Genet. (2000) 97:18994. doi: 10.1002/1096-8628(200023)97:3<189::AID-AJMG1036>3.0.CO;2-J

50. Hipp HS, Charen KH, Spencer JB, Allen EG, Sherman SL. Reproductive and gynecologic care of women with fragile X primary ovarian insufficiency (FXPOI). Menopause. (2016) 23:993-9. doi: 10.1097/GME.00000000000 00658

51. Anasti JN, Kalantaridou SN, Kimzey LM, Defensor RA, Nelson LM. Bone loss in young women with karyotypically normal spontaneous premature ovarian failure. Obstet Gynecol. (1998) 91:12-5. doi: 10.1016/S0029-7844(97)00583-8

52. Ram S, Devapriya IA, Fenton G, Mcvay L, Nguyen DV, Tassone F, et al. Axonal neuropathy in female carriers of the fragile $\mathrm{X}$ premutation with fragile X-associated tremor ataxia syndrome. Muscle Nerve. (2015) 52:234239. doi: $10.1002 /$ mus. 24515

53. Soontarapornchai K, Maselli R, Fenton-Farrell G, Tassone F, Hagerman PJ, Hessl D, et al. Abnormal nerve conduction features in fragile X premutation carriers. Arch Neurol. (2008) 65:495-498. doi: 10.1001/archneur.65.4.495

54. Greco CM, Berman RF, Martin RM, Tassone F, Schwartz PH, Chang A, et al. Neuropathology of fragile X-associated tremor/ataxia syndrome (FXTAS). Brain. (2006) 129:243-55. doi: 10.1093/brain/awh683

55. Hunsaker MR, Greco CM, Spath MA, Smits APT, Navarro CS, Tassone $\mathrm{F}$, et al. Widespread non-central nervous system organ pathology in fragile $\mathrm{X}$ premutation carriers with fragile $\mathrm{X}$-associated tremor/ataxia syndrome and CGG knock-in mice. Acta Neuropathol. (2011) 122:46779. doi: 10.1007/s00401-011-0860-9

56. Gokden M, Al-Hinti JT, Harik SI. Peripheral nervous system pathology in fragile X tremor/ataxia syndrome (FXTAS). Neuropathology. (2009) 29:2804. doi: 10.1111/j.1440-1789.2008.00948.x

57. Ramírez-Cheyne JA, Duque GA, Ayala-Zapata S, Saldarriaga-Gil W, Hagerman P, Hagerman R, et al. Fragile X syndrome and connective tissue dysregulation. Clin Genet. (2019) 95:262-7. doi: 10.1111/cge.13469

58. Tassanakijpanich N, McKenzie FJ, McLennan YA, Makhoul E, Tassone F, Jasoliya MJ, et al. Hypermobile ehlers-danlos syndrome (hEDS) phenotype in fragile X premutation carriers: case series. I Med Genet. (2021). doi: 10.1136/jmedgenet-2020-107609 [online ahead of print].

59. Vu TH, Shipley JM, Bergers G, Berger JE, Helms JA, Hanahan D, et al. MMP-9/Gelatinase B Is a Key Regulator of Growth Plate Angiogenesis and Apoptosis of Hypertrophic Chondrocytes. Cell. (1998) 93:41122. doi: $10.1016 /$ S0092-8674(00)81169-1
60. Wang J, Tsirka SE. Neuroprotection by inhibition of matrix metalloproteinases in a mouse model of intracerebral haemorrhage. Brain. (2005) 128:1622-33. doi: 10.1093/brain/awh489

61. Loesch DZ, Huggins RM, Bui QM, Taylor AK, Hagerman RJ. Relationship of deficits ofFMR1 gene specific protein with physical phenotype of fragile $\mathrm{X}$ males and females in pedigrees: A new perspective. Am J Med Genet. (2003) 118A:127-34. doi: 10.1002/ajmg.a.10099

62. Banfi G, Diani M, Pigatto PD, Reali E. T Cell Subpopulations in the physiopathology of fibromyalgia: evidence and perspectives. Int J Mol Sci. (2020) 21:1186. doi: 10.3390/ijms21041186

63. Üçeyler N, Zeller D, Kahn A-K, Kewenig S, Kittel-Schneider S, Schmid A, et al. Small fibre pathology in patients with fibromyalgia syndrome. Brain. (2013) 136:1857-67. doi: 10.1093/brain/awt053

64. Yunus MB. Towards a model of pathophysiology of fibromyalgia: aberrant central pain mechanisms with peripheral modulation. J Rheumatol. (1992) 19:846-50

65. Rosen S, Ham B, Mogil JS. Sex differences in neuroimmunity and pain. $J$ Neurosci Res. (2017) 95:500-8. doi: 10.1002/jnr.23831

66. Osterweis M, Kleinman A, Mechanic D, editors. Pain and Disability: Clinical, Behavioral, and Public Policy Perspectives. Washington (DC): National Academies Press (1987)

67. Polussa J, Schneider A, Hagerman R. Molecular advances leading to treatment implications for fragile X premutation carriers. Brain Disord Ther. (2014) 3:1000119. doi: 10.4172/2168-975X.1000119

68. Finnerup NB, Attal N, Haroutounian S, McNicol E, Baron R, Dworkin RH, et al. Pharmacotherapy for neuropathic pain in adults: a systematic review and meta-analysis. Lancet Neurol. (2015) 14:162-73. doi: 10.1016/S1474-4422(14)70251-0

69. Muzar Z, Adams PE, Schneider A, Hagerman RJ, Lozano R. Addictive substances may induce a rapid neurological deterioration in fragile Xassociated tremor ataxia syndrome: a report of two cases. Intractable Rare Dis Res. (2014) 3:162-165. doi: 10.5582/irdr.2014.01023

70. Lin W-C, Chou K-H, Chen C-C, Huang C-C, Chen H-L, Lu C-H, et al. White matter abnormalities correlating with memory and depression in heroin users under methadone maintenance treatment. PLoS ONE. (2012) 7:e33809. doi: 10.1371/journal.pone.0033809

71. Li W, Li Q, Wang Y, Zhu J, Ye J, Yan X, et al. Methadone-induced damage to white matter integrity in methadone maintenance patients: a longitudinal self-control DTI study. Sci Rep. (2016) 6:19662. doi: 10.1038/srep19662

72. Kogan CS, Turk J, Hagerman RJ, Cornish KM. Impact of the fragile X mental retardation 1 (FMR1) gene premutation on neuropsychiatric functioning in adult males without fragile $\mathrm{X}$-associated tremor/ataxia syndrome: a controlled study. Am J Med Genet Part B Neuropsychiatr Genet. (2008) 147B:85972. doi: 10.1002/ajmg.b.30685

73. Dorn MB, Mazzacco MMM, Hagerman RJ. Behavioral and psychiatric disorders in adult male carriers of fragile X. J Am Acad Child Adolesc Psychiatry. (1994) 33:256-64. doi: 10.1097/00004583-199402000-00015

74. El-Deeb M, Adams P, Schneider A, Salcedo-Arellano MJ, Tassone F, Hagerman R. Fentanyl overdose in a female with the FMR1 premutation and FXTAS. $J$ Mol Genet. (2018) 1:101. doi: 10.31038/JMG.1000101

75. Chu LF, Angst MS, Clark D. Opioid-induced hyperalgesia in humans. Clin J Pain. (2008) 24:479-96. doi: 10.1097/AJP.0b013e31816b2f43

76. Derry S, Wiffen PJ, Kalso EA, Bell RF, Aldington D, Phillips T, et al. Topical analgesics for acute and chronic pain in adults-an overview of Cochrane Reviews. Cochrane database Syst Rev. (2017) 5:CD008609CD008609. doi: 10.1002/14651858.CD008609.pub2

77. Ramírez-López A, Pastor A, Torre R, La Porta C, Ozaita A, Cabañero $\mathrm{D}$, et al. Role of the endocannabinoid system in a mouse model of Fragile X undergoing neuropathic pain. Eur J Pain. (2021) 25:131628. doi: 10.1002/ejp.1753

78. Wade DT, Robson P, House H, Makela P, Aram J. A preliminary controlled study to determine whether whole-plant cannabis extracts can improve intractable neurogenic symptoms. Clin Rehabil. (2003) 17:219. doi: 10.1191/0269215503cr581oa

79. Palmieri B, Laurino C, Vadalà M. Short-Term Efficacy of CBDEnriched Hemp Oil in Girls with Dysautonomic Syndrome after Human Papillomavirus Vaccination. Isr Med Assoc J. (2017) 19:79-84. 
80. Cuñetti L, Manzo L, Peyraube R, Arnaiz J, Curi L, Orihuela S. Chronic pain treatment with cannabidiol in kidney transplant patients in uruguay. Transplant Proc. (2018) 50:461-4. doi: 10.1016/j.transproceed.2017.12.042

81. Tartaglia N, Bonn-Miller M, Hagerman R. Treatment of Fragile X syndrome with cannabidiol: a case series study and brief review of the literature. Cannabis cannabinoid Res. (2019) 4:3-9. doi: 10.1089/can.2018.0053

82. Heussler H, Cohen J, Silove N, Tich N, Bonn-Miller MO, Du W, et al. A phase $1 / 2$, open-label assessment of the safety, tolerability, and efficacy of transdermal cannabidiol (ZYN002) for the treatment of pediatric fragile X syndrome. J Neurodev Disord. (2019) 11:16. doi: 10.1186/s11689-0199277-x

83. Bergamaschi MM, Queiroz RHC, Chagas MHN, de Oliveira DCG, De Martinis BS, Kapczinski F, et al. Cannabidiol reduces the anxiety induced by simulated public speaking in treatment-naïve social phobia patients. Neuropsychopharmacol. (2011) 36:1219-26. doi: 10.1038/npp. 2011.6

84. Chagas MHN, Eckeli AL, Zuardi AW, Pena-Pereira MA, Sobreira-Neto MA, Sobreira ET, et al. Cannabidiol can improve complex sleep-related behaviours associated with rapid eye movement sleep behaviour disorder in Parkinson's disease patients: a case series. J Clin Pharm Ther. (2014) 39:564-6. doi: 10.1111/jcpt.12179

85. Verma AK, Khan E, Mishra SK, Mishra A, Charlet-Berguerand N, Kumar A. Curcumin regulates the $\mathrm{r}(\mathrm{CGG})$ (exp) RNA hairpin structure and ameliorate defects in Fragile X-associated tremor ataxia syndrome. Front Neurosci. (2020) 14:295. doi: 10.3389/fnins.2020.00295

86. Shokri-Mashhadi N, Bagherniya M, Askari G, Sathyapalan T, Sahebkar A. A Systematic review of the clinical use of curcumin for the treatment of osteoarthritis. $A d v$ Exp Med Biol. (2021) 1291:265-82. doi: 10.1007/978-3-030-5 6153-6_16

87. Napoli E, Flores A, Mansuri Y, Hagerman RJ, Giulivi C. Sulforaphane improves mitochondrial metabolism in fibroblasts from patients with fragile X-associated tremor and ataxia syndrome. Neurobiol Dis. (2021) 157:105427. doi: 10.1016/j.nbd.2021.105427

88. Patte-Mensah C, Meyer L, Taleb O, Mensah-Nyagan AG. Potential role of allopregnanolone for a safe and effective therapy of neuropathic pain. Prog Neurobiol. (2014) 113:70-8. doi: 10.1016/j.pneurobio.2013.07.004

89. Nair AS, Diwan S. Allopregnanolone: A neurosteroid for managing acute and chronic pain conditions. Saudi J Anaesth. (2019) 13:2646. doi: 10.4103/sja.SJA_830_18

90. Meltzer-Brody S, Kanes SJ. Allopregnanolone in postpartum depression: Role in pathophysiology and treatment. Neurobiol Stress. (2020) 12:100212. doi: 10.1016/j.ynstr.2020.100212

91. Wang JY, Trivedi AM, Carrillo NR, Yang J, Schneider A, Giulivi C, et al. Open-label allopregnanolone treatment of men with fragile $\mathrm{X}$-associated tremor/ataxia syndrome. Neurother J Am Soc Exp Neurother. (2017) 14:107383. doi: 10.1007/s13311-017-0555-6

92. Meeus M, Nijs J, Hermans L, Goubert D, Calders P. The role of mitochondrial dysfunctions due to oxidative and nitrosative stress in the chronic pain or chronic fatigue syndromes and fibromyalgia patients: peripheral and central mechanisms as therapeutic targets? Expert Opin Ther Targets. (2013) 17:1081-9. doi: 10.1517/14728222.2013.8 18657

93. Grimm A, Schmitt K, Lang UE, Mensah-Nyagan AG, Eckert A. Improvement of neuronal bioenergetics by neurosteroids: implications for age-related neurodegenerative disorders. Biochim Biophys Acta. (2014) 1842:242738. doi: 10.1016/j.bbadis.2014.09.013

94. Turk DC, Meichenbaum D. A cognitive-behavioral approach to pain management. In: The Evolution of Cognitive Behavior Therapy: A Personal and Professional Journey with Don Meichenbaum. (2017). p. 132-54.

95. Finan PH, Goodin BR, Smith MT. The association of sleep and pain: an update and a path forward. J pain. (2013) 14:153952. doi: 10.1016/j.jpain.2013.08.007

96. Sielski R, Rief W, Glombiewski JA. Efficacy of Biofeedback in Chronic back Pain: a Meta-Analysis. Int J Behav Med. (2017) 24:25-41. doi: 10.1007/s12529-016-9572-9

97. Hilton L, Hempel S, Ewing BA, Apaydin E, Xenakis L, Newberry S, et al. Mindfulness Meditation for Chronic Pain: Systematic Review and Metaanalysis. Ann Behav Med. (2017) 51:199-213. doi: 10.1007/s12160-016-9844-2

98. Manheimer E, White A, Berman B, Forys K, Ernst E. Meta-analysis: acupuncture for low back pain. Ann Intern Med. (2005) 142:65163. doi: 10.7326/0003-4819-142-8-200504190-00014

99. Vickers AJ, Rees RW, Zollman CE, McCarney R, Smith CM, Ellis N, et al. Acupuncture for chronic headache in primary care: large, pragmatic, randomised trial. BMJ. (2004) 328:744. doi: 10.1136/bmj.38029.421863.EB

Conflict of Interest: $\mathrm{RH}$ has received funding from Zynerba and the Azrieli foundation for carrying out treatment studies in patients with fragile $\mathrm{X}$ syndrome. FT has received funding from Zynerba and Asuragen, Inc.

The remaining authors declare that the research was conducted in the absence of any commercial or financial relationships that could be construed as a potential conflict of interest.

Publisher's Note: All claims expressed in this article are solely those of the authors and do not necessarily represent those of their affiliated organizations, or those of the publisher, the editors and the reviewers. Any product that may be evaluated in this article, or claim that may be made by its manufacturer, is not guaranteed or endorsed by the publisher.

Copyright (c) 2022 Johnson, Santos, Kim, Ponzini, McLennan, Schneider, Tassone and Hagerman. This is an open-access article distributed under the terms of the Creative Commons Attribution License (CC BY). The use, distribution or reproduction in other forums is permitted, provided the original author(s) and the copyright owner(s) are credited and that the original publication in this journal is cited, in accordance with accepted academic practice. No use, distribution or reproduction is permitted which does not comply with these terms. 